\title{
CULTIVATION OF COTTON IN WESTERN AFRICA
}

IN writing this title, I cannot help remembering that it is not quite four years ago since I returned from the Sudan with my friend Chevalier, who is now continuing his naturalist mission in the district of Lake Tchad; when people asked our opinion respecting the profit Europeans could obtain from Western Africa, and we answered "cultivate cotton," we were looked upon as Utopian dreamers and almost accused of not understanding anything of a country which we were, however, the first to have studied from an economic point of view.

Since then, matters have changed indeed : societies of encouragement for the culture of cotton in Africa have been formed in Germany and in England, and France has followed the impulse.

Yet, I feel that especially in England and in France the case is considered simpler than it really is, which makes me anxious to inquire into the conditions of the existing problem.

The Germans are unquestionably more advanced in this respect. The best way is to examine first what they have done in Togo. A recent visit to Berlin has allowed us to get better information than we had. ${ }^{1}$

The "Kolonial Wirtschaftliches Komitee," the technical organ of the German Colonial Society, founded in 1900 a society of studies to provide for the expenses of the "Togo Cotton Expedition." The necessary capital was furnished by the German Colonial Society which gave the proceeds of a national lottery started specially for that purpose, and by all the large manufacturers and traders concerned with textile matters.

I Beumwall, Expedition nach Togo-Kolonial Wirtschafiliches Komitec. I br. Berlin. 
The committee, following the line of conduct it had always pursued, confided this mission to specialists and applied to the "Normal and Industrial Institute" of Tuskegee (Alabama, U.S.A.). The director placed at the disposal of the committee Mr. James Calloway, director of the cotton section of the Institute, and three foremen chosen from amongst the certificated members of the Institute, two agriculturists and a mechanic, all three belonging to the black race, and therefore able to withstand the African climate. The equipment was also provided by the Institute : ginning machines, presses, ploughs, agricultural tools, waggons, and seeds.

The expedition went to the Misahohe District, where the seat of the experiments directed by Mr. Calloway was established. At other places in Togo experiments were made by Messrs. Gruner, Schmidt, and Kersting, whose labours confirmed the results obtained by Mr. Calloway; results which we will now consider.

The ground chosen was formed of a sub-soil composed in a great measure of red gravel covered by a layer of humus, thin in the higher and deep in the lower parts. The light soils were chosen for cultures exposed to heavy rains, to enable the water to run off quickly, and thus allow air to reach the roots.

The work began in the middle of January 1901. Two hundred natives were engaged. Men paid by the day were to cut the brushwood; better workmen, coming from the coast, and paid $75 \mathrm{pf}$. were to fell the trees and tear up the roots; women paid 35 pf. and children paid 20 pf. were to gather up the roots and burn them.

The first idea had been to till the land with ploughs, and American-like the expedition had not brought any pickaxes, being convinced that agricultural machines were very superior to hand tools. The mistake was soon perceived, and 50 hectares had to be cleared up by means of pickaxes borrowed from the neighlouring plantations. Twenty oxen and twenty horses were bought in the Sudan for drawing the ploughs and carts. It was found easier to train horses for ploughs than oxen. But the tsetse files appeared and the animals perished in May, June, and September. The greater part of the work had to be done by hand. 
Seed was sown during six months, and Mr. Calloway considers the time can be divided into two periods : from March to June, and from July to August. As soon as the first rains began, 27th March, three-quarters of a hectare was planted with American cotton. The plants grew quicker and better than in America. A month later they had reached a height of $0.50 \mathrm{~m}$. April, in which there was a slight rain, was a good month for sowing. Five hectares were planted with American cotton, and in May the plantation was increased to ten hectares.

Owing to the death of horses, oxen were from that time a great help in preparing the soil for seed.

The month of June appeared very favourable to the growth of the plantations, but very little sowing was done, the rains being too frequent and heavy.

A field for experiments was created in the middle of June; different species of American, native, and Egyptian cotton were planted in ten sections. The manure used and brought by the expedition consisted of phosphoric acid and potash. By the end of the month all the plants had come up successfully.

The cotton planted in March, April, and May had produced good results, when disastrous rains came in July: most of the pods of the first plants were destroyed. The heavy rains were followed by fogs and cold nights, the cotton was covered with mildew, and the pods became mouldy before opening. All the plants sowed before July produced only two bales of cotton, and the field was destroyed.

In July and August, Io hectares were again sowed with Egyptian and American species. The rains were less heavy in September and October, but clouds and fogs were persistent. At the end of October the sun shone, and the temperature was higher; the plants revived, and the light rains of November and December brought what in America would have been called : "Half a crop."

A small extent of ground was sowed in October, but without great success, for the rain that followed later was not abundant enough.

On the whole, from the cultivator's point of view, Mr. Calloway's experiment comes to this : we must wait for sowing 
until the season of heavy rains is well over, and we may thus obtain good results with American species.

And still better results will be obtained if cotton seeds are used as manure-whether the oil has been extracted from them or not-or if artificial manure consisting of potash or phosphoric acid be used.

The American agriculturist considers that by means of crossing American cotton with native cotton, we can create a new species, which, being able to stand the climate, may give a good result as regards both quality and quantity.

This short analysis shows with what care the experiment in Togo was carried on. We may now inquire how far it can be turned to account, and we shall rely on the results obtained by the Germans as to cost to see what practical conclusion may be reached.

The most important question to examine first of all is that of climate.

When speaking of West Africa we must distinguish between the countries of the tropical zone, and those within the 500 kil. extending along the littoral from French Guinea as far as Cameroon. Their climate is as different as are the races which inhabit them.

Among tropical countries we must also distinguish-although it is a matter of less importance-between those countries which we shall call the Sudan proper, which extends from the Niger to the Tchad (to speak only of West Africa) and the districts of Senegal and Gambia.

In fact Senegal has in some parts an almost Saharan climate while in others, as in the border countries of Casamance and the Gambia, the tropical climate is somewhat modified by the presence of rivers, although drier than that of other more southern countries.

On an average there falls yearly in the Sudan but 0.60 per cent. of rain, and the dry season lasts eight months, whereas in the countries along the coast the average rainfall is greater and the dry season shorter.

In Casamance and Gambia there falls about o.7o per cent. 0 rain, the dry season being almost as long as in the tropics.

In the countries farther south, the duration of the dry season 
is much shorter and the drought much less complete, fogs and dews keeping up an almost continuous humidity. The yearly rain on the Gold Coast, Togo, Dahomey, varies in height from Im. 20c. to 2 metres, and falls almost entirely from April to the middle of October.

We must set aside the southern parts of French Guinea and Sierra Leone, in which there falls from 4 to 6 metres of water owing to the existence of forest clad mountains, whence the Niger rises. We have seen how the r.80 per cent. of rainfall in Togo spoiled the cultivated cotton. It is therefore useless to encourage that culture in this zone of diluvial rains, which extends for a distance of 200 kils. at the back of the coast line. There is certainly an indigenous species, but it is almost wild, and the natives have very nearly given up cultivating it in those countries. Climate is indeed the cause of this, and not merely the existence of European cotton goods, as in Dahomey for instance, where these goods penetrate quite as abundantly, the cultivation of cotton has been kept up.

If one plants at the end of the rainy season in Guinea and in Sierra Leone, there is not, as in Togo at the end of the dry season, sufficient moisture for the plants to grow. Therefore our efforts in those countries ought to be turned to the regions of the interior near the Sudan.

With this exception the climate of West Africa is on the whole very suitable for the culture of cotton, on account of the dry season when the crop can be gathered without fear of rain. The experiment of Togo, as was rather to be expected, proved that the Sudan, and in general the tropical countries of Africa, have a climate preferable to that of the countries adjoining the coast, because the rains are less abundant.

Together with the climate we must also take into consideration the nature of the soil.

There is one point which cannot be too thoroughly understood, although it is not the general opinion: it is that the soils of West Africa are imperfect soils. This special feature is only recognised generally in the land of the Sudan, which people following Lord Salisbury, are accustomed to look upon, quite falsely, as barren soils, while the soil of the colonies on the coast is held to be rich. The fact is that often when the 
vegetation appears exuberant, it is simply because the plants of that region have perfectly adapted themselves to the soil ; and if the soil is not modified all intensive culture, or any introduction of new plants, or improvement of indigenous species, is most difficult, if not impossible.

The proof of this is that the natives grow crops in rotation, and only cultivate the same land at intervals of four or five years.

The most serious matter is the total absence of lime in the soil, and there is often very little potash ; besides which, although the ground is fairly charged with vegetable mould, nitrification is often difficult.

The countries of the coast have therefore an advantage over those of the interior, to which it will be more expensive to send chemical manure.

Yet the countries of the interior, the Sudan for instance, will have this advantage over those of the coast, that the harvesting and removal of cultures will be more easy; and here we come to the nature of the labour which will be required to cultivate cotton in West Africa.

Here also the distinction we made respecting climate must be taken into serious consideration. Clearings are in fact much more difficult in countries where the rains are heavy. We may consider that wild vegetation covering the ground is of two kinds-the tall Guinea grass which grows to a height of four metres and the thick brushwood. Of course we do not speak of the great forest regions which must be worked last of all. We may admit in a general way that the whole soil of West Africaexcept the forests-has been put under cultivation by the natives, the brushwood marking the regions where cultivation has longest been given up.

The Sudan offers this advantage: that there brushwood is very rare, outside the region that forms the borderland of the Sahara, which is filled with false gum-trees and mimosas. We must remember, too, that in countries with a partly equatorial climate where fogs and dews maintain a constant vegetation, grasses can only be partially destroyed by means of fire; while in countries with long months of drought vegetable life is stopped almost completely; the brushwood is entirely burnt 
up, and the tearing up of the roots is easier where the ground is left bare. I know it might appear more rational not to burn the grasses but to bury them, but I doubt whether it would be very profitable to do this over large tracts. The fertilising value of these dried-up grasses cannot be much greater than that of their ashes, and the difference would not make up for the extra expense incurred by pulling them up without a preliminary fire. Besides, it would be dangerous to bury dry matter, as the fields would soon be infested by termites attracted by the detritus, and the seeds would soon be devoured. In reference to this, we must not exaggerate the havoc done in the seed plots by termites, unless imprudences such as we have alluded to be committed. In Togo the Germans have experienced some loss arising from this cause, but they do not seem to consider them as very serious. Seeds must germinate rapidly, and as soon as life begins termites attack the plants much less. At any rate, the danger might be avoided by plunging seeds before sown into some liquid, the taste of which would keep the insects away, a plan often practised by the natives.

If lands are more easily cleared in tropical countries than in semi-equatorial ones, the care of the plantations is also easier. Weeds spring up in those humid countries in a most exasperating manner, and long years of work are needed to rid the ground of them. We must thoroughly understand that hoeing is by far a greater expense than clearing or preparing the soil; and not to take that into account would lead to serious disappointments when reckoning the general expenses of cultivation.

In my opinion, the necessity of constant hoeing is the principal obstacle Europeans would find in undertaking the cultivation of plants which would not naturally offer a certain resistance to weeds, or the value of which would not be in proportion to the space required for their cultivation as is the case with groundnuts, sessame, mountain rice, etc.

The distinction we have made between the tropical countries and the semi-equatorial countries of the coast, is moreover felt in the way in which clearing and hoeing can be carried out in West Africa. Only Americans, not understanding the African brushwood, could have started without taking up any other agricultural 
implements than ploughs, as did the members of the Togo expedition, but they soon found out their mistake.

To tear up tufts of roots of the Guinea grasses, when the soil is dried up requires the use of implements that actually break up the ground, and yet the use of such implements has the disadvantage of mixing the poor earth of the subsoil with layers of superficial humus, a matter to be well considered in countries where it is difficult to procure manure.

Besides the existence of tree roots would make the digging in difficult. Until further investigation, we have to accept the fact that in semi-equatorial countries clearings must be made with hatchets and pickaxes.

The clearings once properly made, and in many cases this cannot succeed in the first year, we think the plough ought to be used, as there will no longer be the fear of mixing the superficial humus with the earth of the subsoil, and it is not difficult to work the subsoil with ploughs and scarificators without going deeper than is desirable.

The Togo expedition decided to use the plough for cultivation, but we have seen that it was much impeded by the sickness and mortality among the animals, and this is a difficulty. which will stand in the way of agricultural undertakings on the coast, as oxen and horses are there in a constant state of sickness. However, the head of the Togo expedition does not think it an insurmountable obstacle; he has had ploughs drawn by men and the work was cheaper than that done by pickaxes, but it only corresponded to two-thirds of the work which could have been done by a small horse, and Mr. Calloway gives the following calculation :-

Two months or 50 days of work done by 4 men at the rate of 0.75 pf. a day cost 150 marks, whilst a horse can be bought in Togo for 60,70 , or 80 marks. If it dies after 50 days, it will have done one-third more work than the men, and there will remain a difference of 70,80 , or 90 marks for its keep; and besides it is well known that plough work is preferable to that of man. Therefore the American engineer concludes that we must not be checked by the fact that animals die after a short time of work, since the cost of them has been, so to say, regained. This opinion is corroborated by the experience of the military engineer 
who is constructing the railway in French Guinea. In that country, the animals are almost as sickly in the neighbourhood of the coast as in Togo. Yet it has been found an economy to use them for drawing waggons, until the state of their hoofs unfits them for long work. Moreover healthy animals being killed for the food of the workmen, a part of their value is thus recovered. In Guinea these animals give two months of work which corresponds to what has been obtained by the Togo expedition; yet very robust animals have worked for two years. It would evidently be a gain to study this question more closely.

In the Sudan and in Senegal we shall not be troubled with the problem of the health of animals; the climate agrees with them and they can do good work, besides the species is stronger and gives better results. In some countries, as in the plains near the Niger, the feeding of cattle is much easier owing to the existence of the "bourgon," a sweet plant that forms large pastures in the bed of the river; and the oxen themselves would hardly cost more than 40 or 50 francs, the average price on the coast.

As for the question of labour, the Sudanese lands offer this special advantage that in many districts the clearing can be done by ploughs, as the grasses which cover them are easily pulled up after being burnt.

Nevertheless the use of agricultural implements must remain a complicated question in West Africa, especially at the outset; those therefore who devote themselves to agriculture will require a considerable number of labourers. I will not now insist on the fact that in most cases the necessary labour can be procured. I have already spoken on this matter in the African Society's Journal, and it seems to me that gradually the public will no longer cling to the phrase : "the black man will not work."

Agricultural undertakings have increased already in Congo, Cameroon, Togo, and French Guinea, and not one has been impeded by any difficulty about labourers, unless by the fault of the agents. I repeat again that in this respect the Sudan can offer special facilities, the population being greater than on the coast and more inclined to hard work. At any rate, labourers would be much cheaper. In the plains of the Niger men would probably cost $5 d$. a day, and the children $2 d$.; whilst on the coast the lowest price is $7 \frac{1}{3} d$. for men, and $5 d$. for children. 
On the whole we find that the countries of the interior are in every respect superior to those of the coast for the cultivation of cotton : a more suitable climate, a soil easier to clear and till, the possibility of rotation of crops, the weeds less persistent, greater facilities for the use of agricultural implements and draught animals, and good working people in almost unlimited numbers, whose labour is given at a very cheap rate.

The only point of inferiority is the distance, which causes difficulties in the export of products, and high cost price for artificial manure-reduced it is true by the possibility of getting large quantities of farm manure.

Before going further we must try to understand the details of cost so as to know the actual sum spent in conveying cotton to the coast. We shall thus be better able to arrive at a conclusion.

Before the Togo expedition the position was rather vague; but the results obtained have been so strictly criticised that we are able to trust to them until further investigation, and to start from these results to argue the point.

$\mathrm{Mr}$. Calloway allows that unginned cotton can be bought from the natives at the rate of $25 \mathrm{pf}$. for 3 English pounds. He has found that native cotton, as now produced in West Africa, gave 500 pounds of ginned cotton from 1800 pounds of raw cotton, and the following calculation establishes the net cost of a bale of cotton sent from Togo to Bremen.

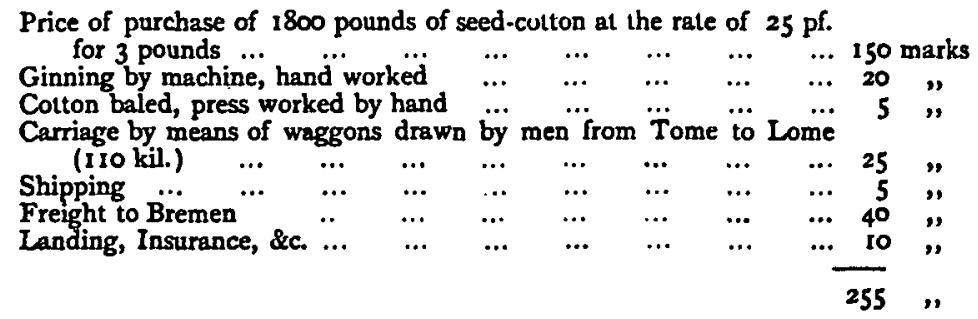

The average price of cotton is at present about $43 \mathrm{pf}$. a pound, which brings the bale of cotton to 215 marks. Mr. Calloway further reckons the value of cotton seed turned into oil on the spot, or used as seed, at 10 marks per 1000 or 1300 pounds, which could be got by treating the 1800 pounds of raw cotton, so that the total value would amount to 225 marks. 
We see therefore that there would be a loss in carrying out the operation.

But if, instead of dealing with native cotton, we succeed in obtaining a new species by means of crossing with improved cotton, which Mr. Calloway thinks feasible, we shall only require I 500 pounds of raw cotton to obtain 500 pounds of this ginned cotton.

If, on the other hand, we use a locomobile to move the machines, Mr. Calloway estimates the cost of ginning at only 10 marks to obtain the bale of 500 pounds. In America that operation only costs one dollar, but in Africa the cost would be higher on account of the price of fuel, repairs of machines, salary of engineers, \&c.

Should steam presses be used the size of the bales would be reduced, the freight lessened in proportion, and the following valuation will be obtained.

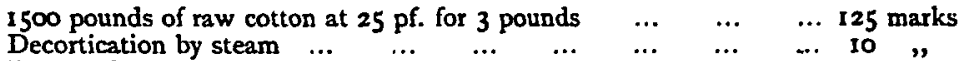

$$
\begin{aligned}
& \begin{array}{llllllllll}
\text { Bale made by steam } & \ldots & \ldots & \ldots & \ldots & \ldots & \ldots & \ldots & \text { 10 } \\
\text {, }
\end{array}
\end{aligned}
$$

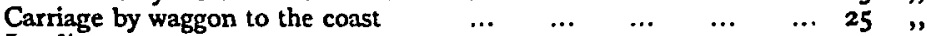

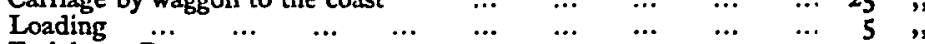

$$
\begin{aligned}
& \begin{array}{lllllllll}
\text { Freight to Bremen } & \ldots & \ldots & \ldots & \ldots & \ldots & \ldots & \ldots & 5
\end{array}
\end{aligned}
$$

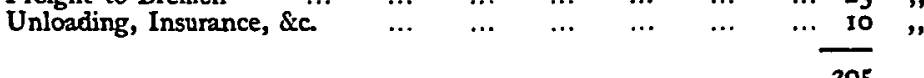

If a railway was constructed connecting the interior with the coast, the carriage, including the freight at $30 \mathrm{pf}$. per kilometric ton, would only cost Io marks, which would bring the price of the bale of 500 pounds conveyed to Bremen to 195 marks, leaving a margin of 30 marks for the sale price, or a little morc than $50 \mathrm{fr}$. for the ton of 1000 kil., a profit which the American agriculturist thinks ought to be considered sufficient by African traders; his report showing that it is equivalent to that they make on palm kernels.

We may gather from these figures many remarkable lessons. First, and above all, how great is the importance we must attach in this business to the question of cultivation, since we find it is only by obtaining improved species that we may hope to turn African cotton to account; further, that the amount set down for carriage is very small.

From prices obtained by the Togo expedition we find the cost 
of transport to the coast is only 200 fr. per ton, which must cover not only the carriage to the coast from the points whence the cotton is drawn, but the general expenses of cultivation, the European staff, the sinking of capital and the profits.

The points nearest to the coast seem therefore to stand first for development, and yet we cannot help maintaining that efforts should be chiefly directed to the interior.

As we have shown, as far as cultivation is concerned, the planter will be in a far better position than on the coast, and we cannot impress this too seriously on our readers. Moreover we must not forget that there are many parts of the interior easy of access, as for instance the banks of such large rivers as are navigable from the sea, the Senegal, the Casamance, and above all the Niger as far as Bousa and Benue.

One illusion we must guard against: there is no point along the coast of Africa-except perhaps on the plains of Senegal and the Saloum-where cultivations like that of cotton can be undertaken: marshes filled with mangroves in French Guinea, Sierra Leone, and the Oil Rivers; sand and forests and lagoons stretching back from the Ivory Coast; such is the coast for about 60 kil. inland.

Railways will therefore be necessary to carry the products from the first districts which can be cultivated, while the very banks of the rivers we have mentioned can be turned to account, and when made valuable will furnish enormous quantities of cotton.

The English are especially favoured in this respect, and we would advise them to carry their first efforts into Nigeria. There they will find populations among whom the cultivation of cotton is already of considerable importance; and the large steamers, going up more than $600 \mathrm{kil}$. into the interior, will carry at a freight a long way below the $50 \mathrm{fr}$. a ton of the supposed railway of Togo.

In the same way the Germans will easily get to that part of the Sudan situated north of Cameroon; we know that in Berlin and Hamburg great interest is taken in those regions, and we think they could continue their remarkable investigations with every possible advantage, and with facilities which they did not possess in Togo. 
As for France, as 1 have said before, she can easily reach tropical regions through the Senegal, the Saloum, and the Casamance, but she is less well off in the Niger regions.

The countries she could reach by the lower Niger are divided from the free part of the river by rapids which without making navigation impossible as was thought at first, will make it difficult and therefore expensive.

I am one of the very few who, with Colonel Toutée and some officers, know the region that extends from Timbuctoo to the English Niger. I have told elsewhere how interesting this region is from Gas onward for its islands, and what rich plains one meets with on leaving Sensa Haoussa towards the Sudan. These, however, are too far removed from points of easy access for us to think of turning our efforts in that direction at present.

We could certainly find markets in English Nigeria for the cattle and the cereals which are so much wanted in that country; but we must first of all consider the rich region of our Niger-the region that extends from its sources to Timbuctoo.

I need not again dwell on the richness of those lands-A. Chevalier has spoken of it already in this Journal-nor of the important problem which lies before us French people, how to utilise the region of inundations for extensive culture by low dykes surrounding the fields and regular distribution of water : the time is past, I hope, when in France people laughed in our faces at the mere mention of this. I simply wish to remind my readers that we can only turn our efforts to real account by means of railways connecting the navigable Niger with the coast from Bamako to Dakar and from Kouroussa to Conakry, and that these railways will get no return loads unless their tariffs are low enough to allow the exportation of products of small value in proportion to their value and their weight.

On the whole, we may consider that in a general way West Africa can be cultivated with advantage even in its most varied regions, and the beautiful Sudanese plains which lend themselves best to this culture are not inaccessible.

And now we come to the question what is the form this cultivation of cotton ought to take in West Africa, and what are the respective parts to be taken in it by Europeans and by natives. 
We must say at once that our opinion in the matter coincides with that of the Togo expedition, which is that we must try to get the natives to confine themselves to the culture of selected species, and sell to Europeans the product of their plantations as they sell ground nuts and palm oil.

But it would be necessary for some years to have model farms worked among them by white experts. For my part, I think these farms absolutely indispensable for two reasons. First, because this is the way to obtain improved or acclimatised species, which alone will make the cultivation of cotton profitable in West Africa ; and secondly, because it is only thus that we shall get the natives to cultivate these species.

Private farming by Europeans might possibly be turned to good account ; but it is uncertain owing to the great cost of exploiting agriculture in West Africa. I believe also, contrary to the general opinion, that mere buying by commercial houses would be fruitless. And in reference to this we must add, however painful it may be, that as long as traders were the only people who troubled themsclves about the development of West Africa-which was the casc for ages until quite lately-the nature of this exploitation of the country always remained the same, apart from the suppression of the slave trade. Hardly any effort has been made to urge the natives to new cultures, or to the cultivation of unworked products.

I speak of what relates to traders, and not of Governments only, like that of the Senegal for instance, of whose efforts to encourage the cultivation of cotton A. Chevalier gave lately a very full account. Those efforts have remained almost everywhere without results, because European traders no longer took any interest in them. I know that the agents and the employes are answerable for that, and not the heads of commercial houses, but it is they who choose their employes, and until lately these have been very second rate from every point of view.

Not only have they not studied the country in order to know what new riches it might offer, but in many cases they are answerable for the failure of trials their firms wished to make.

On principle, the trader of the coast has a horror of a new product. For him it represents not only the unknown, but an increase of work. 
A remarkable instance of this was given about ten years ago in the Senegal. The heads of one of the largest companies on the coast had decided on urging the Negroes to cultivate the castor oil plant. Several tons of good seeds were distributed, and the administration helped in this laudable undertaking. The natives cultivated extensive tracts of land, and when they brought their crops to the agents of the aforesaid company the latter sent them packing, saying they would only buy ground nuts.

If to an entire upsetting of all old habits, we add considerable personal effort, tenacity, and the technical knowledge which would be necessary in the case of cotton as in many other cases, it is pretty certain that we shall not find all these in African trading factories.

We need for this purpose bodies of men who are already familiar with land questions and taking an interest in them. Mr. Calloway thinks that fields for experiments ought to be established close to centres where the whites can buy cotton and gin it, an operation which cannot be performed by the natives. The blacks will then see what care they must give to their cultures, they will learn to use modern tools, and, above all, will be more encouraged to work by seeing the fine crops of the whites than they could be by all the speeches an indifferent employé might address them from behind his counter.

In years to come when this cultivation is definitely established and when all understand its requirements and its results, the whites may be merely buyers; until then they must be buyers and also educators.

I shall not insist on the different means there may be ot acting on the natives, apart from model farms, task-work, or contracts made with the more intelligent heads of houses, and I know many in our French Sudan with whom it will be possible to organise farms on the metayer system. People will then understand that it is not impossible to get good work out of those African peoples which have been so much cried down. I would only before closing insist on the kind of aid which should be given at the outset of this new phase of the agricultural development of West Africa, by the societies of encouragement which are being formed in Germany, in England, and in 
France, thanks to the co-operation of their most important manufacturers and merchants.

We must thoroughly understand that in the matter of agriculture almost everything is, we may say, truly unknown in West Africa. Quiet people at home look at the few planters who are there at present as very bold; and we must own that they need to have great confidence in themselves-for they are isolatedand great enthusiasm for their work not to draw back before the unknown they have to face.

But I shall ever repeat that agriculture must take the first place in the development of those countries, though I cannot deny that every question is peculiarly difficult. It is very difficult to act wisely with people of a race different from our own, and yet it is only by so doing that we can gain anything from them; and I feel that everything is important in this respect, even one's own mode of life. It is very difficult to decide what kind of culture to undertake; and when the choice is made no one yet knows how best to treat the plants and how they will turn out. Should also new species have to be created, which is the case with cotton, this is a thing beyond the power and means of mere planters. For these reasons the societies of encouragement do very right to come to their aid.

In our opinion, Germany, England, and France ought each to establish stations for trying to unravel the main threads of the problem. These stations must be real commercial enterprises on a big scale as were those of Togo; it is only thus that results can be obtained, and not from mere sample gardens. The mistake of these sample gardens is that no direct information can be got by them either as to practical results or as to cost. The model farms ought besides to provide improved seeds, and even for that alone cultivation on a large scale is necessary.

It is not necessary that these stations should be very numerous at first. What is really important is that they be placed in very different situations.

For France I would advise one in the Saloum, another in Dahomey, and another near the interior Delta of the Niger ; for England one between Lokodja and Egga, and another on the line of the Lagos railway, at about a hundred kilometres from 
the coast. As for Germany it seems to me that while continuing the experiment of Togo, she should take it up also in the north of Cameroon near the Benue.

When these typical stations have given results, they can increase their modes of action : subventions given to planters who, already settled in certain regions, can make experiments ; distribution of seeds and trained animals; as also the formation of a staff specially fitted to take the direction of those agricultural centres mentioned by Mr. Calloway, which will be placed near centres easy of access for traders who will purchase the cotton from the growers.

There are at present so many great undertakings in West Africa, that when the time comes their Directors need not hesitate to create such centres of trade. The societies of encouragement will have to guide them and facilitate their task.

Until then they can also use their influence in urging upon the Governments of their respective countries the construction of railways, which must start from the West Coast, and without which Africa would ever remain unprogressive.

The problem of the production of cotton by their colonies is of such importance for European countries, owing to their dependence on America, that they must each of them not only make every possible effort to solve it, but unite for that purpose in communicating to each other the result of their work.

Sir Alfred Jones in Liverpool, and the Kolonial Wirtschaftliches at Berlin, did me the great honour to ask me if I thought my country would make this union possible. It is not in the nature of France to be distrustful, and to stand aloof from efforts made to benefit the interests of humanity; the alliance of the three great European Powers for the improvement of their new territories is too glorious a thing for France not to help it with all her heart. And how remarkable if it were actually in this Darkest Africa, so misunderstood, that the first attempt should be made at a wise economic entente which must be the aim of future ages.

Emile Baillaud,

(Ancien chargé de mission au Soudan Francais. Virecteur de la Société agricole et industrielle

Plantations de Benty, 22 Oclabre, 1902. de la Guinée Franģaise). 